Anal. Theory Appl.

Vol. 28, No. 1 (2012), 1-12

\title{
COMMON FIXED POINTS WITH APPLICATIONS TO BEST SIMULTANEOUS APPROXIMATIONS
}

\author{
Sumit Chandok and T. D. Narang \\ (Guru Nanak Dev University, India)
}

Received Jan. 4, 2010

Abstract. For a subset $K$ of a metric space $(X, d)$ and $x \in X$,

$$
P_{K}(x)=\{y \in K: d(x, y)=d(x, K) \equiv \inf \{d(x, k): k \in K\}\}
$$

is called the set of best $K$-approximant to $x$. An element $g_{\circ} \in K$ is said to be a best simultaneous approximation of the pair $y_{1}, y_{2} \in X$ if

$$
\max \left\{d\left(y_{1}, g_{\circ}\right), d\left(y_{2}, g_{\circ}\right)\right\}=\inf _{g \in K} \max \left\{d\left(y_{1}, g\right), d\left(y_{2}, g\right)\right\} .
$$

In this paper, some results on the existence of common fixed points for Banach operator pairs in the framework of convex metric spaces have been proved. For self mappings $T$ and $S$ on $K$, results are proved on both $T$ - and $S$ - invariant points for a set of best simultaneous approximation. Some results on best $K$-approximant are also deduced. The results proved generalize and extend some results of I. Beg and M. Abbas ${ }^{[1]}$, S. Chandok and T.D. Narang ${ }^{[2]}$, T.D. Narang and S. Chandok ${ }^{[11]}$, S.A. Sahab, M.S. Khan and S. Sessa ${ }^{[14]}$, P. Vijayaraju $^{[20]}$ and P. Vijayaraju and M. Marudai ${ }^{[21]}$.

Key words: Banach operator pair, best approximation, demicompact, fixed point, starshaped, nonexpansive, asymptotically nonexpansive and uniformly asymptotically regular maps

AMS (2010) subject classification: 41A50, 41A60, 41A65, 47H10, 54H25

\section{Introduction}

Let $(X, d)$ be a metric space. A mapping $W: X \times X \times[0,1] \rightarrow X$ is said to be (s.t.b.) a convex structure on $X$ if for all $x, y \in X$ and $\lambda \in[0,1]$

$$
d(u, W(x, y, \lambda)) \leq \lambda d(u, x)+(1-\lambda) d(u, y)
$$

holds for all $u \in X$. The metric space $(X, d)$ together with a convex structure is called a convex metric space ${ }^{[19]}$. 
A convex metric space $(X, d)$ is said to satisfy Property (I) ${ }^{[7]}$ if for all $x, y, p \in X$ and $\lambda \in$ $[0,1]$,

$$
d(W(x, p, \lambda), W(y, p, \lambda)) \leq \lambda d(x, y) .
$$

A normed linear space and each of its convex subset are simple examples of convex metric spaces. There are many convex metric spaces which are not normed linear spaces (see [19]). Property (I) is always satisfied in a normed linear space.

A subset $K$ of a convex metric space $(X, d)$ is s.t.b. convex ${ }^{[19]}$ if $W(x, y, \lambda) \in K$ for all $x, y \in K$ and $\lambda \in[0,1]$. A set $K$ is said to be $p$-starshaped (see [8]) where $p \in K$, provided $W(x, p, \lambda) \in K$ for all $x \in K$ and $\lambda \in[0,1]$ i.e. the segment

$$
[p, x]=\{W(x, p, \lambda): 0 \leq \lambda \leq 1\}
$$

joining $p$ to $x$ is contained in $K$ for all $x \in K$. $K$ is said to be starshaped if it is $p$-starshaped for some $p \in K$.

Clearly, each convex set is starshaped but not conversely.

A self map $T$ on a metric space $(X, d)$ is s.t.b.

i) nonexpansive if $d(T x, T y) \leq d(x, y)$ for all $x, y \in X$;

ii) contraction if there exists an $\alpha, 0 \leq \alpha<1$ such that $d(T x, T y) \leq \alpha d(x, y)$ for all $x, y \in X$.

For a nonempty subset $K$ of a metric space $(X, d)$, a mapping $T: K \rightarrow K$ is s.t.b.

i) demicompact if every bounded sequence $\left\langle x_{n}>\right.$ in $K$ satisfying $d\left(x_{n}, T x_{n}\right) \rightarrow 0$ has a convergent subsequence;

ii) asymptotically nonexpansive [6] if there exists a sequence $\left\{k_{n}\right\}$ of real numbers in $[1, \infty)$ with $k_{n} \geq k_{n+1}, k_{n} \rightarrow 1$ as $n \rightarrow \infty$ such that $d\left(T^{n}(x), T^{n}(y)\right) \leq k_{n} d(x, y)$, for all $x, y \in K$.

Let $T, S: K \rightarrow K$. Then $T$ is s.t.b.

i) $S$-asymptotically nonexpansive if there exists a sequence $\left\{k_{n}\right\}$ of real numbers in $[1, \infty)$ with $k_{n} \geq k_{n+1}, k_{n} \rightarrow 1$ as $n \rightarrow \infty$ such that $d\left(T^{n}(x), T^{n}(y)\right) \leq k_{n} d(S x, S y)$, for all $x, y \in K$;

ii) uniformly asymptotically regular on $K$ if for each $\varepsilon>0$ there exists a positive integer $N$ such that $d\left(T^{n}(x), T^{n}(y)\right)<\varepsilon$ for all $n \geq N$ and for all $x, y \in K$.

A point $x \in K$ is a common fixed (coincidence) point of $S$ and $T$ if $x=S x=T x$ ( $S x=$ $T x$ ). The set of fixed points (respectively, coincidence points) of $S$ and $T$ is denoted by $F(S, T)$ (respectively, $C(S, T)$ ).

The mappings $T, S: K \rightarrow K$ are s.t.b. commuting on $K$ if $S T x=T S x$ for all $x \in K$; $R$-weakly commuting ${ }^{[13]}$ on $K$ if there exists $R>0$ such that

$$
d(T S x, S T x) \leq R d(T x, S x)
$$

for all $x \in K$; compatible ${ }^{[9]}$ if $\lim d\left(T S x_{n}, S T x_{n}\right)=0$ whenever $\left\{x_{n}\right\}$ is a sequence such that $\lim T x_{n}=\lim S x_{n}=t$ for some $t$ in $M$; weakly compatible ${ }^{[10]}$ if $S$ and $T$ commute at their coincidence points, i.e., if $S T x=T S x$ whenever $S x=T x$. 
Suppose $(X, d)$ is a convex metric space, $K$ a $q$-starshaped subset with $q \in F(S) \cap K$ and is both $T$ and $S$-invariant. Then $T$ and $S$ are called

i) $R$-subcommuting ${ }^{[16]}$ on $K$ if for all $x \in K$, there exists a real number $R>0$ such that

$$
d(T S x, S T x) \leq(R / k) \operatorname{dist}(S x, W(T x, q, k)), \quad k \in(0,1] ;
$$

ii) $R$-subweakly commuting ${ }^{[15]}$ on $K$ if for all $x \in K$, there exists a real number $R>0$ such that $d(T S x, S T x) \leq R \operatorname{dist}(S x, W(T x, q, k)), k \in[0,1]$;

iii) uniformly $R$-subweakly commuting (see[1]) on $K$ if for all $x \in K$, there exists a real number $R>0$ such that

$$
d\left(T^{n} S x, S T^{n} x\right) \leq R \operatorname{dist}\left(S x, W\left(T^{n} x, q, k\right)\right), \quad k \in[0,1] .
$$

Chen and $\mathrm{Li}^{[4]}$ introduced the class of Banach operator pairs, as a new class of noncommuting pairs. The ordered pair $(T, I)$ of two self maps of a metric space $(X, d)$ is called a Banach operator pair, if the set $F(I)$ of fixed points of $I$ is $T$-invariant, i.e. $T(F(I)) \subseteq F(I)$. Obviously, commuting pair $(T, I)$ is a Banach operator pair but not conversely (see [4]). If $(T, I)$ is a Banach operator pair then $(I, T)$ need not be Banach operator pair (see [4]). If the self maps $T$ and $I$ of $X$ satisfy $d(I T x, T x) \leq k d(I x, x)$, for all $x \in X$ and for some $k \geq 0, I T x=T I x$ whenever $x \in F(I)$ i.e. $T x \in F(I)$, then $(T, I)$ is a Banach operator pair. In particular, when $I=T$, the above inequality can be rewritten as $d\left(T^{2} x, T x\right) \leq k d(T x, x)$ for all $x \in X$. Such a $T$ is called a Banach operator of type $k$ (see [17], [18]). This class of non-commuting mappings is different from the class of non-commuting mappings (viz. $R$-weakly commuting, $R$-subweakly commuting, compatible, weakly compatible etc.) existing in the literature (see $[3,4,12,13,15,16])$. Hence the concept of Banach operator pair is of basic importance for the study of common fixed points.

Example 1.1. Let $X=\mathbf{R}$ with usual metric and $K=[1, \infty)$. Let $T(x)=x^{3}$ and $I(x)=2 x-1$, for all $x \in K$. Then $F(I)=\{1\}$. Here $(T, I)$ is a Banach operator pair but $T$ and $I$ are not commuting.

Example 1.2 $2^{[5]}$. Consider $X=R^{2}$ with usual metric $d\left(\left(x_{1}, y_{1}\right),\left(x_{2}, y_{2}\right)\right)=\left|x_{1}-x_{2}\right|+\mid y_{1}-$ $y_{2} \mid,\left(x_{1}, y_{1}\right),\left(x_{2}, y_{2}\right) \in \mathbf{R}^{2}$. Define $T$ and $I$ on $X$ as $T(x, y)=\left(x^{3}+x-1, \frac{\sqrt[3]{x^{2}+y^{3}-1}}{3}\right)$ and $I(x, y)=$ $\left(x^{3}+x-1, \sqrt[3]{\left.x^{2}+y^{3}-1\right)} . F(T)=(1,0), F(I)=\{(1, y): y \in R\}\right.$ and $C(I, T)=\{(x, y): y=$ $\left.\sqrt[3]{1-x^{2}}, x \in R\right\} . T(F(I))=\{T(1, y): y \in R\}=\left\{\left(1, \frac{y}{3}\right): y \in R\right\} \subseteq\{(1, y): y \in R\}=F(I)$. Thus $(T, I)$ is a continuous Banach operator pair, which is not weakly compatible as $T$ and $I$ do not commute on the set $C(I, T)$ and hence it is not compatible.

In this paper, we prove some results on the existence of common fixed points for Banach operator pairs in the framework of convex metric spaces. For self mappings $T$ and $S$ on $K$, results are also proved on both $T$ - and $S$ - invariant points for a set of best simultaneous approximation. Some results on best $K$-approximant are also deduced. The results proved in the paper generalize and extend some of the results of Beg and Abbas ${ }^{[1]}$, Chandok and Narang ${ }^{[2]}$, Narang and Chandok ${ }^{[11]}$, Sahab, Khan and Sessa ${ }^{[14]}$, Vijayaraju ${ }^{[20]}$ Vijayaraju and Marudai ${ }^{[21]}$. 


\section{Main Results}

\subsection{Common Fixed Point Theorems}

In this section we prove some results on the existence of common fixed points for Banach operator pairs in convex metric spaces.

We need the following lemma of Chen and $\mathrm{Li}$ [4] for our theorems.

Lemma 2.1. Let $D$ be a closed subset of a metric space $(X, d)$, and $S, T$ self maps of $D$. Suppose that $T$ is $S$-contraction and the pair $(T, S)$ is a Banach operator pair. If $\overline{T(D)}$ is complete, $S$ is continuous and $F(S)$ is nonempty, then $F(T) \cap F(S)$ is a singleton.

Theorem 2.2. Let $D$ be a complete and bounded subset of a convex metric space $(X, d)$ with Property (I), $S$ and $T$ be self mappings of $D$. If $D$ is q-starshaped with $q \in F(S), T$ is demicompact, $S$ is continuous and $F(S)$ is starshaped with respect to $q,(T, S)$ is a Banach operator pair and $T$ is $S$-nonexpansive, then $S$ and $T$ have a common fixed point in $D$.

Proof. Define $T_{n}$ as $T_{n}(x)=W\left(T x, q, a_{n}\right)$ for all $x \in D$ where $<a_{n}>$ is a sequence in $(0,1)$ such that $a_{n} \rightarrow 1$. Since $D$ and $F(S)$ are $q$-starshaped, $T_{n}$ is a self map of $D$ for each $n$. Since $(T, S)$ is a Banach operator pair and $F(S)$ is starshaped with respect to $q \in F(S)$, so for each $x \in F(S), T_{n}(x)=W\left(T x, q, a_{n}\right) \in F(S)$ since $T x \in F(S)$. Thus $\left(T_{n}, S\right)$ is a Banach operator pair for each $n$.

Since $T$ is $S$-nonexpansive, we have

$$
d\left(T_{n} x, T_{n} y\right)=d\left(W\left(T x, z, a_{n}\right), W\left(T y, z, a_{n}\right)\right) \leq a_{n} d(T x, T y) \leq a_{n} d(S x, S y) .
$$

Therefore each $T_{n}$ is a $S$-contraction on $D$. Also, $D$ is complete, and $S$ is continuous on $D$ and so by Lemma 2.1, there is a point $x_{n}$ in $D$ such that $x_{n}=T_{n} x_{n}=S x_{n}$. Consider

$$
\begin{aligned}
d\left(x_{n}, T x_{n}\right) & =d\left(T_{n} x_{n}, T x_{n}\right) \leq d\left(W\left(T x_{n}, q, a_{n}\right), T x_{n}\right) \\
& \leq a_{n} d\left(T x_{n}, T x_{n}\right)+\left(1-a_{n}\right) d\left(q, T x_{n}\right) \\
& \rightarrow 0 \text { as } a_{n} \rightarrow 1 .
\end{aligned}
$$

Since $D$ is bounded, $T$ is demicompact, $\left\langle x_{n}>\right.$ has a convergent subsequence $<x_{n_{i}}>\rightarrow z \in D$. Since $T$ is $S$-nonexpansive and $S$ is continuous, so $T x_{n_{i}} \rightarrow T z$. Therefore

$$
d(z, T z) \leq d\left(z, x_{n_{i}}\right)+d\left(x_{n_{i}}, T x_{n_{i}}\right)+d\left(T x_{n_{i}}, T z\right) \rightarrow 0,
$$

$T z=z$. Since $S$ is continuous and $x_{n_{i}}=S\left(x_{n_{i}}\right), z=S z$. Hence $S$ and $T$ have a common fixed point in $D$.

Taking $S=I$ (the identity mapping), we have:

Corollary $\mathbf{2 . 3}^{[2]}$. Let $D$ be a nonempty complete bounded starshaped subset of a convex metric space $(X, d)$ with Property (I). If $T$ is a nonexpansive and demicompect self mapping of $D$, then $T$ has a fixed point in $D$. 
Corollary $2.4^{[7]}$. Let D be a nonempty compact starshaped subset of a convex metric space $(X, d)$ with Property $(I)$ and $T$ be a nonexpansive self mapping of $D$, then $T$ has a fixed point in $D$.

Proof. Since $D$ is compact, starshaped and $T$ is continuous, $T$ is compact and so demicompact. The result now follows from Corollary 2.3.

Remarks 2.5. a. In comparison with the theorem of Chandok and Narang ${ }^{[2]}$ and Vijayaraju and Marudai ${ }^{[21]}$, the commutativity of the maps $T$ and $S$ is replaced by the hypothesis that $(T, S)$ is a Banach operator pair. Moreover, the requirement of affinity of $S$ is relaxed by merely assuming that $F(S)$ is starshaped. In addition, the condition that $T(D) \subseteq S(D)$ is also dropped.

b. In comparison with the theorem of Vijayaraju and Marudai ${ }^{[21]}$, the commutativity of the maps $T$ and $S$ is replaced by the hypothesis that $(T, S)$ is a Banach operator pair. Moreover, the requirement of affinity of $S$ is relaxed by merely assuming that $F(S)$ is starshaped. In addition, the condition that $T(D) \subseteq S(D)$ is also dropped and the spaces undertaken are convex metric spaces.

Theorem 2.6. Let $D$ be a nonempty closed subset of a convex metric space $(X, d)$ with Property (I), $S$ and $T$ be self mappings of $D$ and $q \in F(S)$. If $D$ is q-starshaped, cl $(T(D))$ is compact, $S$ is continuous and $F(S)$ is q-starshaped, $(T, S)$ is a Banach operator pair and $T$ is $S$-asymptotically nonexpansive and asymptotically regular, then $S$ and $T$ have a common fixed point in $D$.

Proof. For each $n$, define $T_{n}: D \rightarrow D$ as $T_{n}(x)=W\left(T^{n} x, q, a_{n}\right), x \in D$, where

$$
a_{n}=\frac{1-\frac{1}{n}}{k_{n}}
$$

and $\left\{k_{n}\right\}$ is a sequence of real numbers in $[1, \infty)$ with $k_{n} \geq k_{n+1}, k_{n} \rightarrow 1$. Since $D$ and $F(S)$ are $q$-starshaped, $(T, S)$ is a Banach operator pair and so for each $x \in F(S), T(x) \in F(S)$, it follows that $T_{n}(x)=W\left(T^{n} x, q, a_{n}\right) \in F(S)$ for each $n$. Thus $\left(T_{n}, S\right)$ is a Banach operator pair for each $n$. Since $T$ is $S$-asymptotically nonexpansive, it follows that

$$
\begin{aligned}
d\left(T_{n}(x), T_{n}(y)\right) & =d\left(W\left(T^{n} x, q, a_{n}\right), W\left(T^{n} x, q, a_{n}\right)\right) \\
& \leq a_{n} d\left(T^{n} x, T^{n} y\right) \\
& \leq a_{n} k_{n} d(S x, S y) \\
& =\frac{1-\frac{1}{n}}{k_{n}} k_{n} d(S x, S y) \\
& =\left(1-\frac{1}{n}\right) d(S x, S y)
\end{aligned}
$$

i.e. $T_{n}$ is $S$-contraction. Since $\operatorname{cl}(T(D))$ is compact and $T$ is continuous, $\operatorname{cl}\left(T_{n}(D)\right)$ is also compact. Hence by Lemma 2.1, there exists $x_{n} \in D$ such that $x_{n} \in F\left(T_{n}, S\right)$ for each $n \in N$. Since $\left\{T^{n} x_{n}\right\}$ is a sequence in the compact set $c l(T(D))$, there exists a subsequence $\left\{T^{n_{i}} x_{n_{i}}\right\}$ of $\left\{T^{n} x_{n}\right\}$ such that

$$
T^{n_{i}} x_{n_{i}} \rightarrow z \in \operatorname{cl}(T(D)) .
$$


Therefore

$$
x_{n_{i}}=T_{n_{i}} x_{n_{i}}=W\left(T^{n_{i}}\left(x_{n_{i}}\right), q, a_{n_{i}}\right) \rightarrow z .
$$

Since $S$ is continuous and $S\left(x_{n_{i}}\right)=x_{n_{i}}$, it follows that $z \in F(S)$. Since T is $S$-asymptotically nonexpansive and $S$ is continuous, it follows that

$$
d\left(T^{n_{i}} x_{n_{i}}, T^{n_{i}} z\right) \leq k_{n_{i}} d\left(S x_{n_{i}}, S z\right) \rightarrow 0 .
$$

Therefore,

$$
\lim T^{n_{i}} x_{n_{i}}=\lim T^{n_{i}} z=z
$$

Since $S$ is continuous, $\lim S T^{n_{i}}(z)=S z$. Since $T$ is asymptotically regular and $S(z)=z$, it follows that

$$
\begin{aligned}
d(z, T z) & \leq d\left(z, T^{n_{i}} z\right)+d\left(T^{n_{i}} z, T^{n_{i}+1} z\right)+d\left(T^{n_{i}+1} z, T z\right) \\
& \leq d\left(z, T^{n_{i}} z\right)+d\left(T^{n_{i}} z, T^{n_{i}+1} z\right)+k_{1} d\left(S\left(T^{n_{i}}(z)\right), S z\right) \\
& \rightarrow 0 .
\end{aligned}
$$

Hence $z \in F(T, S)$.

Remarks 2.7. a. In comparison with Theorem 2.6 of Vijayaraju and Marudai ${ }^{[21]}$, the commutativity of maps $T$ and $S$ is relaxed by the hypothesis that $(T, S)$ is a Banach operator pair. Moreover, the requirement of affinity of $S$ is relaxed by merely assuming that $F(S)$ is starshaped. In addition, the condition that $T(D) \subseteq S(D)$ is also dropped and the spaces undertaken are convex metric spaces.

b. In comparison with Theorem 3.4 of Beg and Abbas ${ }^{[1]}$, uniformily $R$-subweakly commutativity of maps $T$ and $S$ is relaxed by the hypothesis that $(T, S)$ is a Banach operator pair. Moreover, the requirement of affinity/linearity of $S$ is relaxed by merely assuming that $F(S)$ is starshaped. In addition, the condition that $T(D) \subseteq S(D)$ and $S(D)=D$ is also dropped.

Theorem 2.8. Let $D$ be a nonempty complete bounded subset of a convex metric space $(X, d)$ with Property $(I)$, $S$ and $T$ be self mappings of $D$ with $T(D) \subseteq S(D)$ and $q \in F(S)$. If $D$ is $q$-starshaped, $T$ is demicompact, $S$ is continuous and $F(S)$ is $q$-starshaped, $(T, S)$ is a Banach operator pair and $T$ is $S$-asymptotically nonexpansive and asymptotically regular, then $S$ and $T$ have a common fixed point in $D$.

Proof. Defining

$$
T_{n}(x)=W\left(T^{n} x, q, a_{n}\right)
$$

and proceeding as in Theorem 2.6, we see that each $T_{n}$ is $S$-contraction and so by Lemma 2.1, there exists $x_{n} \in D$ such that $x_{n} \in F\left(T_{n}, S\right)$ for each $n \in \mathbf{N}$. Therefore,

$$
\begin{aligned}
d\left(x_{n}, T^{n} x_{n}\right) & =d\left(T_{n} x_{n}, T^{n} x_{n}\right) \\
& =d\left(W\left(T^{n} x_{n}, q, a_{n}\right), T^{n} x_{n}\right) \\
& \leq a_{n} d\left(T^{n} x_{n}, T^{n} x_{n}\right)+\left(1-a_{n}\right) d\left(q, T^{n} x_{n}\right) \\
& \rightarrow 0
\end{aligned}
$$


Since

$$
x_{n}=T_{n} x_{n}=S\left(x_{n}\right),
$$

$T$ is $S$-asymptotically nonexpansive and asymptotically regular, it follows that

$$
\begin{aligned}
d\left(x_{n}, T x_{n}\right) & \leq d\left(x_{n}, T^{n} x_{n}\right)+d\left(T^{n} x_{n}, T^{n+1} x_{n}\right)+d\left(T^{n+1} x_{n}, T x_{n}\right) \\
& \leq d\left(x_{n}, T^{n} x_{n}\right)+d\left(T^{n} x_{n}, T^{n+1} x_{n}\right)+k_{1} d\left(S\left(T^{n}\left(x_{n}\right)\right), S x_{n}\right) \\
& =d\left(x_{n}, T^{n} x_{n}\right)+d\left(T^{n} x_{n}, T^{n+1} x_{n}\right)+k_{1} d\left(T^{n}\left(S x_{n}\right), S x_{n}\right) \\
& =d\left(x_{n}, T^{n} x_{n}\right)+d\left(T^{n} x_{n}, T^{n+1} x_{n}\right)+k_{1} d\left(T^{n} x_{n}, x_{n}\right) \\
& \rightarrow 0 .
\end{aligned}
$$

Since $T$ is demicompact, $\left\{x_{n}\right\}$ has a subsequence $\left\{x_{n_{i}}\right\}$ such that

$$
x_{n_{i}} \rightarrow z \in D .
$$

Since $T$ is continuous, $T\left(x_{n_{i}}\right) \rightarrow T z$. Therefore,

$$
d(z, T z) \leq d\left(z, x_{n_{i}}\right)+d\left(x_{n_{i}}, T x_{n_{i}}\right)+d\left(T x_{n_{i}}, T z\right) \rightarrow 0 .
$$

Hence Tz=z. Since $S$ is continuous and $x_{n_{i}}=S\left(x_{n_{i}}\right)$, it follows that $\mathrm{Sz}=\mathrm{z}$. Thus $z \in F(T, S)$.

Remark 2.9. In comparison with Theorem 2.7 of Vijayaraju and Marudai ${ }^{[21]}$, the commutativity of maps $T$ and $S$ is relaxed by the hypothesis that $(T, S)$ is a Banach operator pair. Moreover, the requirement of affinity of $S$ is relaxed by merely assuming that $F(S)$ is starshaped. In addition, the condition that $T(D) \subseteq S(D)$ is also dropped and the spaces undertaken are convex metric spaces.

Taking $S$ to be an identity map, we get:

Corollary 2.10. Let $D$ be a nonempty complete bounded starshaped subset of a convex metric space $(X, d)$ with Property (I). If $T$ is asymptotically nonexpansive and asymptotically regular and demicompact self mapping of $D$, then $T$ has a fixed point in $D$.

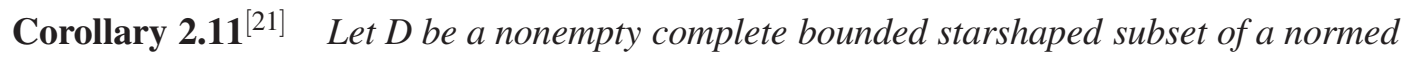
linear space $X$. If $T$ is asymptotically nonexpansive and asymptotically regular and demicompact self mapping of $D$, then $T$ has a fixed point in $D$.

\subsection{Applications to Best and Best Simultaneous Approximation}

In this section we obtain some results on best and best simultaneous approximation as fixed points of Banach operator pairs in the framework of convex metric spaces.

Theorem 2.12. let $T, S: X \rightarrow X$ be operators, $K$ be a subset of a convex metric space $(X, d)$ with Property (I), such that $T: \partial K \rightarrow K$ and $u \in F(T) \cap F(S)$. If the set $D$ of best $K$-approximants 
to u is nonempty, compact $q$-starshaped with $q \in F(S)$, S is continuous, $F(S)$ is starshaped with respect to $q,(T, S)$ is a Banach operator pair on $D \cup\{u\}$ and $T$ is $S$-nonexpansive and satisfies

$$
d(T x, u) \leq d(x, u)
$$

for each $x \in D$, then $S$ and $T$ have a common fixed point in $D$.

Proof. Since $D$ is the set of best approximant to $u$ and

$$
d(T x, u) \leq d(x, u)
$$

for all $x \in D, T x$ is in $D$. Thus $T$ maps $D$ into itself. Define $T_{n}$ as $T_{n}(x)=W\left(T x, q, a_{n}\right)$ for all $x \in D$ where $\left\langle a_{n}\right\rangle$ is a sequence in $(0,1)$ such that $a_{n} \rightarrow 1$. Since $D$ and $F(S)$ are $q$ starshaped, $T_{n}$ is a self map of $D$ for each $n$. Since $(T, S)$ is a Banach operator pair and $F(S)$ is starshaped with respect to $q \in F(S)$, so that for each $x \in F(S), T_{n}(x)=W\left(T x, q, a_{n}\right) \in F(S)$, since $T x \in F(S)$. Thus $\left(T_{n}, S\right)$ is a Banach operator pair for each $n$. Since $T$ is $S$-nonexpansive, we have

$$
\begin{aligned}
d\left(T_{n} x, T_{n} y\right) & =d\left(W\left(T x, q, a_{n}\right), W\left(T y, z, a_{n}\right)\right) \\
& \leq a_{n} d(T x, T y) \\
& \leq a_{n} d(S x, S y) .
\end{aligned}
$$

Therefore each $T_{n}$ is a $S$-contraction on $D$. Also, $D$ is compact, and $S$ is continuous on $D$ and so by Lemma 2.1, there is a point $x_{n}$ in $D$ such that

$$
x_{n}=T_{n} x_{n}=S x_{n}
$$

for each $n$.

Since $D$ is compact, $\left\langle x_{n}\right\rangle$ has a convergent subsequence $\left\langle x_{n_{i}}>\rightarrow z \in D\right.$. Since $S$ is continuous and $x_{n_{i}}=S\left(x_{n_{i}}\right), z=S z$. Since $T$ is $S$-nonexpansive and $S$ is continuous, we have

$$
\begin{aligned}
d\left(x_{n_{i}}, T z\right) & =d\left(T_{n_{i}} x_{n_{i}}, T z\right) \\
& =d\left(W\left(T x_{n_{i}}, q, a_{n_{i}}\right), T z\right) \\
& \leq a_{n_{i}} d\left(T x_{n_{i}}, T z\right)+\left(1-a_{n_{i}}\right) d(q, T z) \\
& \leq a_{n_{i}} d\left(S x_{n_{i}}, z\right)+\left(1-a_{n_{i}}\right) d(q, T z) \\
& \rightarrow 0 .
\end{aligned}
$$

$T z=z$. Hence $S$ and $T$ have a common fixed point in $D$.

Remark 2.13. In comparison with Theorem 3 of Sahab, Khan and Sessa ${ }^{[14]}$ the commutativity of the maps $T$ and $S$ is replaced by the hypothesis that $(T, S)$ is a Banach operator pair. Moreover, the requirement of linearity of $S$ is relaxed by merely assuming that $F(S)$ is starshaped. In addition, the condition that $S(D)=D$ is also dropped and the spaces undertaken are convex metric spaces. 
Theorem 2.14. Let $K$ be a nonempty subset of a convex metric space $(X, d)$ with Property (I), $T$ and $S$ are continuous self-mappings of $K$ such that $T$ is $S$-asymptotically nonexpansive and $F(S)$ is nonempty. Suppose that $y_{1}, y_{2} \in X$ and the set $D$ of best simultaneous approximation to $y_{1}$ and $y_{2}$ is nonempty, compact and starshaped with respect to $z \in F(S)$. Suppose that $T$ satisfies

$$
d\left(T x, y_{i}\right) \leq d\left(x, y_{i}\right)
$$

for all $x \in X$ and $i=1,2$. If the pair $(T, S)$ is a Banach operator pair on $D, T$ is uniformly asymptotically regular on $D$ and $F(S)$ is starshaped with respect to $z \in F(S)$, then $D$ contains $T$ - and $S$ - invariant point.

Proof. Since $D$ is the set of best simultaneous approximation to $y_{1}$ and $y_{2}$ and $d\left(T x, y_{i}\right) \leq$ $d\left(x, y_{i}\right)$ for all $x \in K$ and $i=1,2, T x$ is in $D$. Thus $T$ maps $D$ into itself. Since $T$ is $S$ asymptotically nonexpansive, there exists a sequence $\left\{k_{n}\right\}$ of real numbers in $[1, \infty)$ with $k_{n} \geq$ $k_{n+1}, k_{n} \rightarrow 1$ as $n \rightarrow \infty$ such that

$$
d\left(T^{n}(x), T^{n}(y)\right) \leq k_{n} d(x, y),
$$

for all $x, y \in K$. Suppose that $z$ is a star-center of $D$. Define $T_{n}$ as $T_{n}(x)=W\left(T^{n} x, z, a_{n}\right)$ for all $x \in D$ where

$$
a_{n}=(1-1 / n) / k_{n} .
$$

Since $(T, S)$ is a Banach operator pair and $F(S)$ is starshaped with respect to $z \in F(S)$, so that for each $x \in F(S)$ and $T x \in F(S)$, we have

$$
T_{n}(x)=W\left(T^{n} x, z, a_{n}\right) \in F(S)
$$

for each $n$. Thus $\left(T_{n}, S\right)$ is a Banach operator pair for each $n$.

Since $T$ is $S$-asymptotically nonexpansive, we have

$$
\begin{aligned}
d\left(T_{n} x, T_{n} y\right) & =d\left(W\left(T^{n} x, z, a_{n}\right), W\left(T^{n} y, z, a_{n}\right)\right) \\
& \leq a_{n} d\left(T^{n} x, T^{n} y\right) \\
& \leq a_{n} k_{n} d(S x, S y) \\
& =\left((1-(1 / n)) / k_{n}\right) k_{n} d(S x, S y) \\
& =(1-(1 / n)) d(S x, S y) .
\end{aligned}
$$

Therefore each $T_{n}$ is a $S$-contraction on $D$. Also, $D$ is compact and $T$ is continuous on $D$ and so by Lemma 2.1, there is a point $x_{n}$ in $D$ such that

$$
x_{n}=T_{n} x_{n}=S x_{n} .
$$


Therefore

$$
\begin{aligned}
d\left(x_{n}, T^{n} x_{n}\right) & =d\left(T_{n} x_{n}, T^{n} x_{n}\right) \\
& =d\left(W\left(T^{n} x_{n}, z, a_{n}\right), T^{n} x_{n}\right) \\
& \leq a_{n} d\left(T^{n} x_{n}, T^{n} x_{n}\right)+\left(1-a_{n}\right) d\left(z, T^{n} x_{n}\right) \\
& \rightarrow 0 .
\end{aligned}
$$

Since $T$ is uniformly asymptotically regular and $S$-asymptotically nonexpansive on $D$ and $x_{n}=$ $T_{n} x_{n}=S x_{n}$, it follows that

$$
\begin{aligned}
d\left(x_{n}, T x_{n}\right) \leq & d\left(x_{n}, T^{n} x_{n}\right)+d\left(T^{n} x_{n}, T^{n+1} x_{n}\right)+d\left(T^{n+1} x_{n}, T x_{n}\right) \\
\leq & d\left(x_{n}, T^{n} x_{n}\right)+d\left(T^{n} x_{n}, T^{n+1} x_{n}\right)+k_{1} d\left(S\left(T^{n} x_{n}\right), S\left(x_{n}\right)\right) \\
= & d\left(x_{n}, T^{n} x_{n}\right)+d\left(T^{n} x_{n}, T^{n+1} x_{n}\right)+k_{1} d\left(S\left(T^{n} x_{n}\right), S\left(T_{n} x_{n}\right)\right) \\
= & d\left(x_{n}, T^{n} x_{n}\right)+d\left(T^{n} x_{n}, T^{n+1} x_{n}\right)+k_{1} d\left(S\left(T^{n} x_{n}\right), T_{n}\left(S x_{n}\right)\right) \\
= & d\left(x_{n}, T^{n} x_{n}\right)+d\left(T^{n} x_{n}, T^{n+1} x_{n}\right)+k_{1} d\left(S\left(T^{n} x_{n}\right), W\left(T^{n} S x_{n}, z, a_{n}\right)\right) \\
\leq & d\left(x_{n}, T^{n} x_{n}\right)+d\left(T^{n} x_{n}, T^{n+1} x_{n}\right)+k_{1}\left(a_{n} d\left(S T^{n} x_{n}, T^{n} S x_{n}\right)\right. \\
& \left.+\left(1-a_{n}\right) d\left(S T^{n} x_{n}, z\right)\right) \\
\rightarrow & 0 .
\end{aligned}
$$

Since $D$ is compact, $\left\{x_{n}\right\}$ has a subsequence $\left\{x_{n_{i}}\right\}$ such that $x_{n_{i}} \rightarrow x \in D$. Since $T$ is continuous, $T\left(x_{n_{i}}\right) \rightarrow T(x)$, and so

$$
d(x, T x) \leq d\left(x, x_{n_{i}}\right)+d\left(x_{n_{i}}, T x_{n_{i}}\right)+d\left(T x_{n_{i}}, T x\right) \rightarrow 0,
$$

which gives $T x=x$. Since $S$ is continuous and $x_{n_{i}}=S\left(x_{n_{i}}\right)$, it follows that $S x=x$. Hence $x \in F(T, S)$.

If $y_{1}=y_{2}=x$, we have

Corollary 2.15. Let $K$ be a nonempty subset of a convex metric space $(X, d)$ with Property (I), $T$ and $S$ continuous self-mappings of $K$ such that $T$ is $S$-asymptotically nonexpansive and $F(S)$ is nonempty. Suppose that the set $D$ of best $K$-approximants to $x$ is nonempty, compact and starshaped with respect to $z \in F(S)$, and $D$ is invariant under $T$. If the pair $(T, S)$ is a Banach operator pair on $D, T$ is uniformly asymptotically regular on $D$ and $F(S)$ is starshaped with respect to $z \in F(S)$, then $D$ contains $T$ - and $S$ - invariant point.

Remarks 2.16. a. In comparison with the theorem of Narang and Chandok ${ }^{[11]}$, the uniform $R$-subweakly commutativity of the maps $T$ and $S$ is replaced by the hypothesis that $(T, S)$ is a Banach operator pair. Moreover, the requirement of affinity of $S$ is relaxed by merely assuming that $F(S)$ is starshaped. In addition, the condition that $S(D)=D$ is also dropped.

b. In comparison with the theorem of Narang and Chandok ${ }^{[11]}$, the commutativity of the maps $T$ and $S$ is replaced by the hypothesis that $(T, S)$ is a Banach operator pair. Moreover, the 
requirement of affinity of $S$ is relaxed by merely assuming that $F(S)$ is starshaped. In addition, the condition that $S(D)=D$ is also dropped.

c. In comparison with the theorem of Vijayaraju ${ }^{[20]}$, the commutativity of the maps $T$ and $S$ is replaced by the hypothesis that $(T, S)$ is a Banach operator pair. Moreover, the requirement of affinity of $S$ is relaxed by merely assuming that $F(S)$ is starshaped. In addition, the condition that $S(D)=D$ is also dropped and the spaces undertaken are convex metric spaces.

d. Comparing Corollary 2.15 with Corollary 4.4 of Narang and Chandok ${ }^{[11]}$, the commutativity of the maps $T$ and $S$ is replaced by the hypothesis that $(T, S)$ is a Banach operator pair. Moreover, the requirement of affinity of $S$ is relaxed by merely assuming that $F(S)$ is starshaped. In addition, the condition that $S(D)=D$ is also dropped.

\section{References}

[1] Beg, I. and Abbas, M., Common Fixed Points and Best Approximation in Convex Metric Spaces, Soochow J. Math., 33(2007), 729-738.

[2] Chandok, S. and Narang, T. D., On Fixed Points and Common Fixed Points of Nonexpansive Mappings, Math. Notae 45(2008-09), 51-57.

[3] Chandok, S. and Narang, T. D., Some Common Fixed Point Theorems for Banach Operator P airs with Applications in Best Approximation, Nonlinear Analysis-TMA, 73(2010), 105-109.

[4] Chen, J. and Li, Z., Common Fixed Points for Banach Operator Pairs in Best Approximations, J. Math. Anal. Appl., 336(2007), 1466-1475.

[5] Ćirić, L., Hussain, N. and Cakić, N., Common Fixed Points for Ćirić type $f$-weak Contraction with Applications, Publ. Math. Debrecen, (2009), 1-19.

[6] Goebel, K. and Kirk, W. A., A Fixed Point Theorem for Asymptotically Nonexpansive Mappings, Proc. Amer. Math. Soc., 35 (1972), 171-174.

[7] Guay, M. D. Singh, K. L. and Whitfield, J. H. M., Fixed Point Theorems for Nonexpansive Mappings in Convex Metric Spaces, Proc. Conference on Nonlinear Analysis (Ed. S.P. Singh and J.H. Bury) Marcel Dekker , 80(1982), 179-189.

[8] Itoh, S., Some Fixed Point Theorems in Metric Spaces, Fund. Math., 52(1979), 109-117.

[9] Jungck, G., Common Fixed Points for Commuting and Compatible Maps on Compacta, Proc. American Math. Soc., 103(1988), 977-983.

[10] Jungck, G. and Rhoades, B. E., Fixed Point for Set Valued Functions Without Continuity, Indian J. Pure Appl. Math., 29(1998), 227-238

[11] Narang. T. D. and Chandok, S., Some Fixed Point Theorems with Applications to Best Simultaneous Approximations, J. Nonlinear Sci. Appl., 3(2010), 87-95.

[12] Narang, T. D. and Chandok, S., Common Fixed Points and Invariant Approximation of $R$-subweakly Commuting Maps in Convex Metric Spaces, Ukrainian Math. J., 62 (2010), 1367-1376/1585-1596.

[13] Pant, R. P., Common Fixed Points of Noncommuting Mappings, J. Math. Anal. Appl., 188(1994), 436-440.

[14] Sahab, S. A., Khan, M. S. and Sessa, S., A Result in Best Approximation Theory, J. Approx. Theory, 55 (1988), 349-351.

[15] Shahzad, N., Invariant Approximations and $R$-subweakly Commuting Maps, J. Math. Anal. Appl., 257:1(2001), 39-45.

[16] Shahzad, N., Noncommuting Maps and Best Approximations, Radovi Mat., 10(2001), 77-83. 
[17] Subrahmanyam, P. V., Remarks on Some Fixed Point Theorems Related to Banach's Contraction Principle, J. Math. Phys. Sci., 8 (1974), 445-457, Erratum: J. Math. Phys. Sci. 9(1975), 195.

[18] Subrahmanyam, P. V., An Application of a Fixed Point Theorem to Best Approximation, J. Approx. Theory, 20(1977), 165-172.

[19] Takahashi, W., A Convexity in Metric Space and Nonexpansive Mappings I, Kodai Math. Sem. Rep., 22(1970), 142-149.

[20] Vijayaraju, P., Applications of Fixed Point Theorems to Best Simultaneous Approximations, Indian J. Pure Appl. Math., 24(1993), 21-26.

[21] Vijayaraju, P. and Marudai, M., Some Results on Common Fixed Points and Best Approximations, Indian J. Math., 46(2004), 233-244.

Department of Mathematics

Guru Nanak Dev University

Amritsar, 143005

India

Sumit Chandok

Department of Mathematics

Khalsa College of Engineering (Punjab Technical University)

Ranjit, AMritsar-143001( Punjab)

India

E-mail: chansok.s@gmail.com; chandhok.sumit@gamil.com

T. D. Narang

E-mail: tdnarang1948@yaho0.co.in 